\title{
ESSENTIAL NORM OF GENERALIZED COMPOSITION OPERATORS ON WEIGHTED HARDY SPACES
}

\author{
AJAY K. SHARMA \\ Abstract. Upper and lower bounds for the essential norm of generalized composition operators \\ on weighted Hardy spaces are estimated. \\ Mathematics subject classification (2010): Primary 47B33, 46E10; Secondary 30D55. \\ Keywords and phrases: Generalized composition operator, weighted Hardy space, boundedness, es-
} sential norm, unit disk.

\section{REFERENCES}

[1] K. Avetis Yan, Hardy Bloch-type spaces and lacunary series on the polydisk, Glasgow J. Math. 49 (2007), 345-356.

[2] G. Benke And D. C. ChAng, A note on weighted Bergman spaces and the Cesáro operator, Nagoya Math. J. 159 (2000), 25-43.

[3] C. C. COWEN AND B. D. MACCLUeR, Composition operators on spaces of analytic functions, CRC press, Boca Raton, New York, 1995.

[4] Ž. ČUČKOVIĆ AND R. ZHAO, Weighted composition operators on the Bergman space, J. London Math. Soc. 70 (2004), 499-511.

[5] H. Hedelmalm, B. Korenblum, And K. Zhu, Theory of Bergman Spaces, Springer, New York, 2000.

[6] K. Kellay And P. LeFÈVRe, Compact composition operators on weighted Hilbert spaces of analytic functions, J. Math. Anal. Appl. 386 (2012), 718-727.

[7] S. Li AND S. STEviĆ, Composition followed by differentiation from mixed-norm spaces to $\alpha$-Bloch spaces, Sb. Math 199 (2008), 1847-1857.

[8] S. Li AND S. STEVIĆ, Generalized composition operators on Zygmund spaces and Bloch type spaces, J. Math. Anal. Appl. 338 (2008), 1282-1295.

[9] S. LI AND S. STEVIĆ, Products of integral-type operators and composition operators between Blochtype spaces, J. Math. Anal. Appl. 349 (2009), 596-610.

[10] C. PAN, On an integral-type operator from $Q_{K}(p, q)$ spaces to $\alpha$-Bloch spaces, Filomat 25 (2011), $163-173$.

[11] A. K. Sharma, Volterra composition operators between Bergman-Nevanlinna and Bloch-type spaces, Demonstratio Math. 42 (2009), 607-618.

[12] A. K. Sharma, Products of multiplication, composition and differentiation between weighted Bergman-Nevanlinna and Bloch-type spaces, Turk. J. Math. 35 (2011), 275-291.

[13] A. K. ShARMA, Generalized composition operators between Hardy and weighted Bergman spaces, Acta Sci. Math. 78 (2012), 187-211.

[14] A. K. Sharma, Weighted composition operators from Cauchy integral transforms to logarithmic weighted-type spaces, Ann. Funct. Anal. 4 (2013), 163-174.

[15] A. Sharma AND A. K. Sharma, Carleson measures and a class of generalized Integration operators on the Bergman space, Rocky Mountain J. of Math., 41 (2011), 1711-1724.

[16] A. K. Sharma And S. Ueki, Composition operators from Nevanlinna type space to Bloch type spaces, Banach J. Math. Anal. 6 (2012), 112-123.

[17] S. STEVIĆ, Norm and essential norm of composition followed by differentiation from $\alpha$-Bloch spaces to $H_{\mu}^{\infty}$, Appl. Math. Comput. 207 (2009), 225-229. 
[18] S. STEVIĆ, On a new integral-type operator from the Bloch space to Bloch-type spaces on the unit ball, J. Math. Anal. Appl. 354 (2009), 426-434.

[19] S. STEVIĆ, On an integral operator from the Zygmund space to the Bloch-type space on the unit ball, Glasg. J. Math. 51 (2009), 275-287.

[20] S. STEvić, Products of composition and differentiation operators on the weighted Bergman space, Bull. Belg. Math. Soc. Simon Stevin 16 (2009), 623-635.

[21] S. STEVIĆ, Norm and essential norm of an integral-type operator from the Dirichlet space to the Bloch-type space on the unit ball, Abstr. Appl. Anal. Vol. 2010, Article ID 134969, (2010), 9 pages.

[22] S. STEVIĆ, On an integral operator between Bloch-type spaces on the unit ball, Bull. Sci. Math. 134 (2010), 329-339.

[23] S. STEVIĆ, On an integral-type operator from logarithmic Bloch-type spaces to mixed-norm spaces on the unit ball, Appl. Math. Comput. 215 (2010), 3817-3823.

[24] S. Stević And A. K. Sharma, Essential norm of composition operators between weighted Hardy spaces, Appl. Math. Comput., 217 (2011) 6192-6197.

[25] S. Stević And A. K. Sharma, Composition operators from the space of Cauchy transforms to Bloch and the little Bloch-type spaces on the unit disk, Appl. Math. Comput., 217 (2011) 1018710194.

[26] S. STEVIĆ AND A. K. Sharma, Integral-type operators from Bloch-type spaces to $Q_{K}$ spaces, Abstr. Appl. Anal. (2011) Article ID 698038, 16 pages.

[27] S. Stević, A. K. Sharma and A. Bhat, Products of composition multiplication and differentiation between weighted Bergman spaces, Appl. Math. Comput., 217 (2011), 8115-8125.

[28] S. STEVIĆ, A. K. SHARMA AND A. B HAT, Essential norm of products of composition multiplication and differentiation between weighted Bergman spaces, Appl. Math. Comput., 218 (2011), 2386-2397.

[29] S. Stević And A. K. Sharma, Generalized composition operators on weighted Hardy spaces, Appl. Math. Comput., 218 (2012) 8347-8352.

[30] S. I. UEKI AND L. LUO, Essential norms of weighted composition operators between weighted Bergman spaces of the ball, Acta Sci. Math. (Szeged) 74 (2008), 829-843.

[31] W. YAnG, On an integral-type operator between Bloch-type spaces, Appl. Math. Comput. 215 (3) (2009), 954-960.

[32] W. Yang And X. Meng, Generalized composition operators from $F(p, q, s)$ spaces to Bloch-type spaces, Appl. Math. Comput. 217 (6) (2010), 2513-2519.

[33] K. ZHU, Operator Theory and Function Spaces, Pure and Applied Mathematics 139, Marcel Dekker, Inc., New York and Basel, 1990.

[34] X. ZHU, Generalized weighted composition operators from Bloch-type spaces to weighted Bergman spaces, Indian J. Math. 49 (2) (2007), 139-149.

[35] X. ZHU, Products of differentiation, composition and multiplication from Bergman type spaces to Bers spaces, Integral Transform. Spec. Funct. 18 (3) (2007), 223-231. 